Bulgarian Academy of Sciences. Space Research and Technology Institute.

Aerospace Research in Bulgaria. 29, 2017, Sofia

\title{
HIGH SPEED SOLAR WIND STREAMS OVER THE LAST FOUR SOLAR CYCLES
}

\author{
Yana Asenovska, Simeon Asenovski \\ Space Research and Technology Institute - Bulgarian Academy of Sciences \\ e-mail: asenovski@space.bas.bg
}

\begin{abstract}
Studying the high speed solar wind streams (HSS) behavior over the course of a solar cycle (SC) can give a valuable knowledge about solar activity. Using the experimental data for the solar wind parameters close to Earth, the variation of the HSS over the last four SC $(21 \div 24)$ is shown. While the HSS velocity and appearance for the SC $21 \div 23$ have similar distribution - the maximum of both is around declining phase of solar activity cycle; the situation in SC 24 is not well defined. For the last 24 cycle 302 HSS events were isolated and their maximum speed was estimated.
\end{abstract}

\section{Introduction}

According to the flow properties, the near-Earth's solar wind generally is treated as a three component system: high speed streams (HSS), slow solar wind and streams associated with coronal mass ejections (CME) [1]. The frequency of occurrence and intensity of these three components depends strongly on the phase of the solar activity cycle, as large scale Sun's magnetic field modulates the expansion of the solar wind [2]. HSS are characterized with high speed (>500 km/s), high proton temperature and low plasma density. They originate from coronal holes, which are unipolar open magnetic field areas [3-5]. HSS and $\mathrm{CME}$ are the main types of solar generated drivers that affect Earth. The strong sporadic storms during maximum are caused by CMEs [5, 6], and especially by magnetic clouds with strong and smoothly rotating magnetic field inside the structure providing prolonged periods of southward $B z$ [7].

Coronal holes are the largest and the most geoeffective during the sunspot declining phase [8], when a second maximum in the geomagnetic activity is observed (the first maximum is caused by $\mathrm{CME}$ ).

\section{High speed solar wind streams for solar cycles $21 \div 23$}

The periods of HSS for solar cycles $21 \div 23$ are determined by several catalogues: [9-11]. In Fig. 1 and Fig. 2 averaged values of the maximum speed of 
the HSS (red line), duration of the HSS (blue line) and sunspot number (black line) are presented.

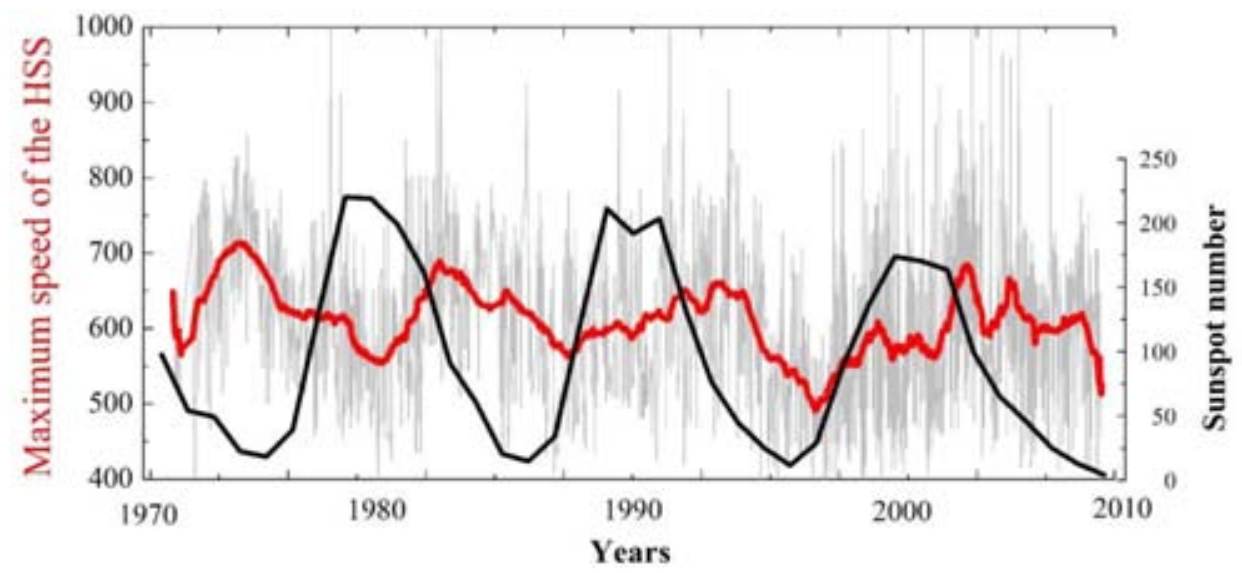

Fig. 1. Maximum speed of the HSS for solar cycles $21 \div 23$

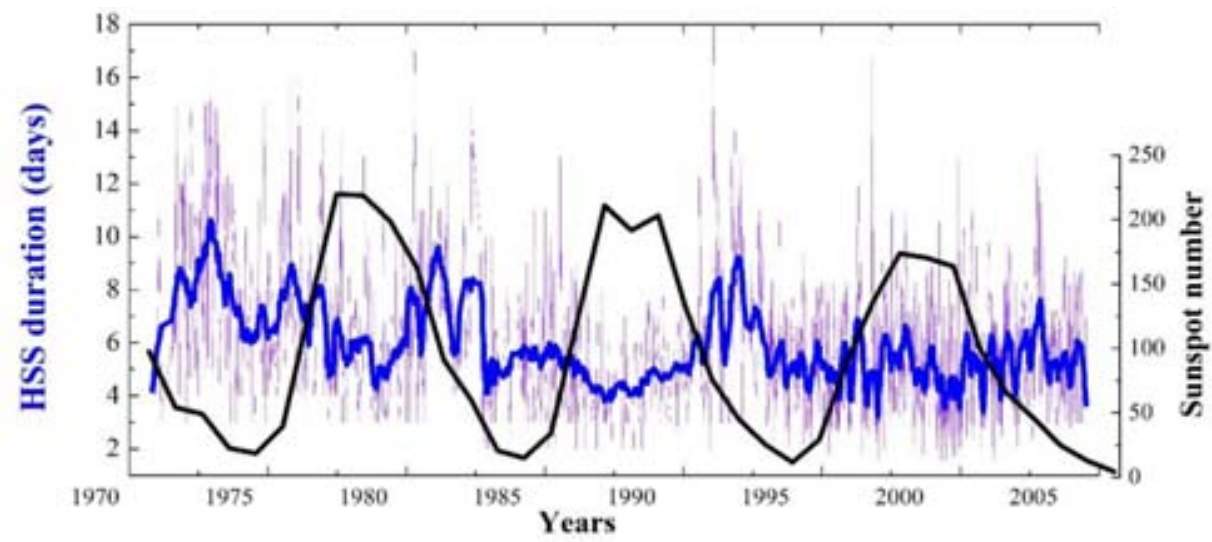

Fig. 2. Duration of the HSS for solar cycles $21 \div 23$

\section{High speed solar wind streams for 24 solar cycle}

In order to characterize the HSS, we have used the hourly values of the plasma parameters gathered in OMNI data base (http://omniweb.gsfc.nasa.gov/) and the identifying criteria for a HSS which include an increase of the solar wind velocity by at least $100 \mathrm{~km} / \mathrm{s}$ in no more than one day to at least $450 \mathrm{~km} / \mathrm{s}$ for at least five hours along with high proton temperature and low plasma density. 
For the last 24 cycles we have isolated 302 HSS events and estimated their maximum speed.

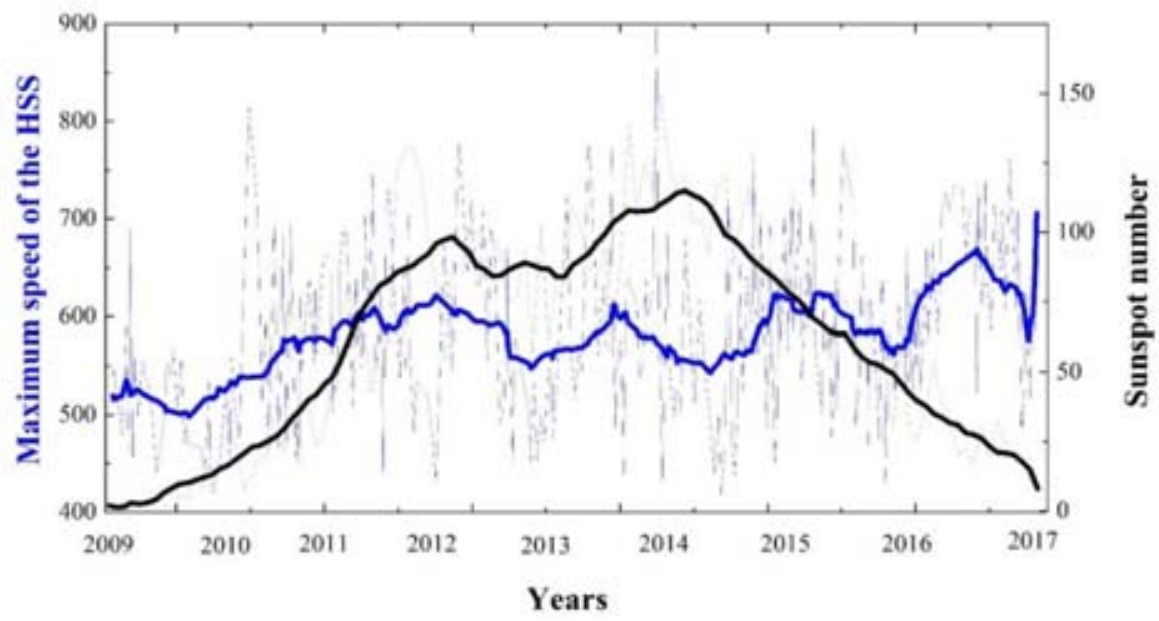

Fig. 3. Maximum speed of the HSS for 24 solar cycle

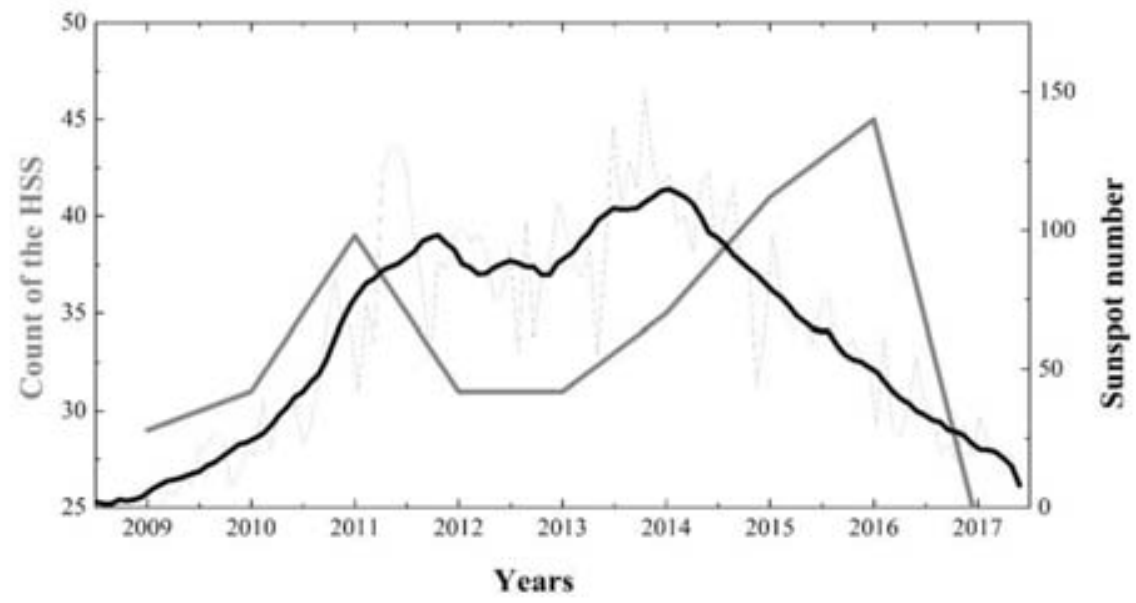

Fig. 4. Count of the HSS for 24 solar cycle

\section{Conclusion}

The results of the presented work can be summarized as:

- During the descending phase of the solar cycles $21 \div 23$ the highest values of maximum HSS speed is observed. 
- The duration of the HSS is the longest ( $8 \div 10$ days) during the descending phase of the solar cycles $21 \div 23$.

- 302 HSS events have been isolated for the last $24^{\text {th }}$ solar cycle and their maximum speed was estimated.

- The profile of the maximum speed of HSS within the $24^{\text {th }}$ solar cycle is different compared to the previous solar cycles and no maximum value is observed.

- The count of the HSS is the greatest during the descending phase of $24^{\text {th }}$ solar cycle.

\section{Acknowledgments}

This work was supported by the National Science Fund under Competition for financial support for projects of junior researchers - 2016, grant № DM 04/4 from 14.12.2016 "Investigation of the impulsive solar activity agents throughout the 11-year solar cycle".

\section{References}

1. Richardson, I.G., H.V. Cane, Solar wind drivers of geomagnetic storms during more than four solar cycles, J. Space Weather Space Clim., 2012, A01, DOI: $10.1051 / \mathrm{swsc} / 2012001$.

2. Pneuman, G.W., R.A. Kopp, Gas-Magnetic Field Interactions in the Solar Corona, Solar Physics, 1971, Vol18, 2, 258-270. DOI: 10.1007/BF00145940.

3. Krieger, A.S., A.F. Timothy, and E.C. Roelof, A coronal hole and its identication as the source of a high velocity solar wind stream, Sol. Phys., 1973, 29, 2, pp. 505-525.

4. Sheeley, Jr. N.R., J.W. Harvey, and W.C. Feldman, Coronal holes, solar wind streams, and recurrent geomagnetic disturbances: 1973-1976, Sol. Phys., 1996, 49, pp. 271-278.

5. Tsurutani, B.T., W.D. Gonzalez, F. Tang, and Y.T. Lee, Great magnetic storms, Geophysical Research Letters, 1992, 19, 1, pp. 73-76.

6. Echer, E., W.D. Gonzalez, B.T. Tsurutani, and A.L.C. Gonzalez, Interplanetary conditions causing intense geomagnetic storms (Dst $=-100 \mathrm{nT}$ ) during solar cycle 23 (19962006), J. Geophys. Res., 2008, 113, A05221, DOI: 10.1029/2007JA012744.

7. Georgieva, K., B. Kirov, and E. Gavruseva, Geoefectiveness of deferent solar drivers, and long-term variations of the correlation between sunspot and geomagnetic activity, Physics and Chemistry of the Earth, 2006, 31, pp. 1-3, 81.

8. Phillips, J., S.J. Bame, W.C. Feldman, J.T. Gosling, C.M. Hammond, D.J. McComas, B.E. Goldstein, M. Neugebauer, E.E. Scime, and S.T. Suess, Ulysses Solar Wind Plasma Observations at High Southerly Latitudes, Science, 1995, 268, 1030-33.

9. Lindblad, B., A. Lundstedt, H. A catalogue of high-speed plasma streams in the solar wind, Solar physics, 1981, 74, pp. 197-206.

10. Mavromichalaki, H., Vassilaki, A., Fast plasma streams recorded near the Earth during 1985-1996, Solar physics, 1998, 183, pp. 181-200. 
11. Xystouris, G., E. Sigala, and H. Mavromichalaki. A complete catalogue of high-speed solar wind streams during solar cycle 23. Solar Physics, 2014, 289, 3, pp. $995-1012$.

\title{
ВИСОКОСКОРОСТНИ ПОТОЦИ БЪРЗ СЛЬНЧЕВ ВЯТЬР ПРЕЗ ПОСЛЕДНИТЕ ЧЕТИРИ СЛЬНЧЕВИ ЦИКЪЛА
}

\author{
Я. Асеновска, С. Асеновски
}

\begin{abstract}
Резюме
Изучаването на поведението на високоскоростните потоци бърз сльнчев вятър (БСВ) може да даде ценни сведения за сльнчевата активност. Използвайки експериментални данни за параметрите на сльнчевия вятър близо до Земята, тази работа показва вариациите на БСВ през последните четири слънчеви цикъла $(21 \div 24)$. Докато появяването и скоростта на БСВ имат сходно разпределение за слънчевите цикли $21 \div 23$ - максимални стойности и на двете периодът на спадане на слънчевата активност, то подобно поведение по време на 24 сльнчев цикъл не се наблюдава. За последния 24 цикъл са определени 302 БСВ събития и са изчислени техните максимални скорости.
\end{abstract}

